\title{
Votar con los pies. Una respuesta a la crisis de la democracia
}

\section{Vote with the Feet. A Response to the Crises of Democracy}

\author{
Jorge A. Rodríguez Martínez \\ Universidad Nacional Autónoma de México \\ jorge.rodriguez@comunidad.unam.mx \\ orcid.org/oooo-ooo2-5478-8564
}

Resumen: En la actualidad, saltan a la vista los múltiples cuestionamientos dirigidos contra las instituciones democráticas. Comúnmente se afirma que la crisis por la que atraviesa la democracia representativa se debe a la ausencia de estas instituciones. En el presente artículo se pretende mostrar lo contrario: que es causada por su exceso y por las contradicciones de los principios que la sostienen. Por esa razón, se revisa de manera crítica la categoría de 'ciudadano'. Dicha noción se encuentra en la base de la lógica del poder soberano. Todos los derechos y responsabilidades reconocidos por el Estado se desprenden de ella. Sin embargo, se trata de una fórmula asimétrica pues es potestad de la entidad soberana conceder y retirar la ciudadanía. Así, ser sujeto de derechos implica estar sujeto al derecho. La triada Estado-territorio-vida constituye una reducción de la existencia del singular a una condición precaria. En este sentido, las nuevas dinámicas sociales invitan a pensar nuevas formas de filiación a la comunidad política que no reduzcan, como la ciudadanía, al singular a la nuda vida.

Palabras clave: ciudadanía, nomos, soberanía, nomadismo, democracia representativa, votar con los pies

Abstract: At present, there are many questions about democratic institutions. Commonly, some argue that the crisis representative democracy is going through is caused by their absence. The present article tries to prove the contrary and establish that the crisis was caused because of their excessive present and due to contradictions between the principles that hold them together. Therefore, a critical review of the concept of "citizen" is offered. The sovereign logic is grounded on this notion. State recognition of legal rights and obligations comes under this category. However, this is an asymmetrical form. Exclusively, the Sovereign has the authority to grant and deprive of citizenship. Thus, 
being a legal subject implies being subject to Law. The State-territorylife triad implies a reduction of singular existence to a precarious condition. In this sense, new social dynamics focus on new forms of membership in political community that do not sacrifice the singular existence, as well as citizenship, to bare life.

Keywords: citizenship, nomos, sovereignty, nomadism, representative democracy, vote with the feet

Recibido: $\quad 18$ de septiembre de 2019

Aceptado: $\quad 17$ de marzo de 2020

No tiene más suelo que el que necesitan sus dos pies, ni más apoyo que el que cubren sus dos manos, es decir mucho menos que el trapecista del circo, que además tiene una red tendida debajo. A nosotros, los demás, a nosotros nos sostienen nuestro pasado y futuro, pasamos casi todo nuestro tiempo de ocio y gran parte de nuestro trabajo haciéndolos subir y bajar, manteniéndolos en equilibrio. Diarios, otoño de 1910, Franz Kafka

A mediados de la década de los noventa, el filósofo italiano Giorgio Agamben lanzó una polémica sentencia con la que inicia la serie de Homo Sacer: el Lager -el campo de concentración - es el nomos que articula la política contemporánea. ${ }^{1}$

Cuando nuestro tiempo ha tratado de dar una localización visible permanente a eso ilocalizable, el resultado ha sido el campo de concentración. No la cárcel, sino el campo de concentración es, en rigor, el espacio que corresponde a esta estructura originaria del nomos [...]. El campo, como espacio absoluto de excepción, es topológicamente diverso de un simple espacio de reclusión. Y es este espacio de excepción en el que el nexo entre localización y orden jurídico se rompe definitivamente, el que ha determinado la crisis del viejo "nomos de la tierra” (Agamben 2010: 33).

1 Tanto en español como en italiano, Giorgio Agamben traduce Lager como campo. Sin duda, esta traducción es precisa. Sin embargo, se ha optado por recurrir al concepto de 'campo de concentración' pues hace una referencia aún más clara al fenómeno histórico concreto, el genocidio nazi. Por Lager, Agamben no solo entiende un espacio de barbarie, sino también una forma jurídica que se apega a la lógica excepcional, pues la norma se aplicaba mediante su suspensión. Al explicitar la figura del "campo de concentración" se pretende, tal como lo hace Agamben, evidenciar la continuidad que persiste entre la normalidad y la excepción. 
En aquel momento, pocos comprendieron la seriedad de la advertencia. La gran mayoría rechazó esta hipótesis, pues muchos aseguraban que los Lager habían quedado enterrados en el pasado, junto con los regímenes totalitarios. Se trataba, afirmaban, de una figura de barbarie que no tenía lugar en las democracias contemporáneas. Debido a la comprensión progresiva de su historia, los Estados formalmente democráticos asumieron que se había aprendido del pasado y, por tanto, se garantizaba la no repetición. Se llegó a conocer a detalle el desarrollo de los sucesos y, sin embargo, se renunció a una comprensión profunda del genocidio. ${ }^{2}$

Las investigaciones historiográficas han sido capaces de reconstruir las circunstancias materiales, técnicas, jurídicas y burocráticas que hicieron posible la instauración de los campos de concentración. Sin embargo, poca atención se ha prestado al significado ético-político del exterminio. Por ello, sostiene Agamben, la comprobación de los hechos acontecidos en Auschwitz no coincide con su comprensión. ${ }^{3}$

Esta incomprensión tiene lugar porque, desde un principio, Auschwitz fue planteado como una fábrica de muerte y, sobre todo, como un programa amnésico, bajo el cual la memoria de la víctima no tenía cabida. En términos políticos, la memoria no solo es honrar el pasado o garantizar la no repetición; también es actualizar las demandas de justicia. Esto solo es posible al remitirse a un sufrimiento concreto. En su sentido político, la memoria permite vincular un acontecimiento singular con el proceso civilizatorio, marcado por la violencia. El nazismo no es una locura, sino la constatación de las consecuencias extremas del sueño de un mundo organizado racionalmente.

2 “[...] el Holocausto fue el resultado del encuentro único de factores que, por sí mismos eran corrientes y vulgares. Y que dicho encuentro resultó posible en gran medida por la emancipación del Estado político — de su monopolio de la violencia y de sus audaces ambiciones de ingeniería social- del control social, como consecuencia del progresivo desmantelamiento de las fuentes de poder y de las instituciones no políticas de la autorregulación social" (Bauman 2011: 18).

3 "Entre querer comprender demasiado, y demasiado deprisa, de los que tienen explicaciones para todo y la negativa a comprender de los sacralizadores a cualquier precio, nos ha parecido que el único camino practicable es el de detenerse sobre esa divergencia. A esta dificultad se añade otra, que afecta en particular a quien está habituado a ocuparse de textos literarios o filosóficos. Muchos testimonios, tanto de los verdugos como de las víctimas, proceden de hombres comunes, y gente 'oscura' era obviamente la gran mayoría de los que se encontraban en los campos. Una de las lecciones de Auschwitz es, precisamente, que entender la mente de un hombre común es infinitamente más arduo que comprender la mente de Spinoza o de Dante..." (Agamben 2000: 9). 
Al estigmatizar el nazismo como antítesis de la modernidad se negó de antemano la posibilidad de reconocer el trasfondo de la Solución final. ${ }^{4}$ En su lógica se reproducían los patrones normativos del mundo moderno, la racionalidad científica y burocrática. ${ }^{5}$ Por ese sesgo, las interpretaciones tradicionales, tanto en el campo de la historia, la filosofía y la política, señalaban que el nazismo se había originado por un desarrollo fallido, que tuvo funestos resultados tras la crisis de la República de Weimar. Según esta perspectiva negacionista, Alemania, en su desarrollo histórico, siguió un "camino único" - Sonderweg - pues no había logrado establecer un sistema de gobierno parlamentario, una cultura democrática y una sociedad igualitaria. Se sostenía que, a diferencia de los británicos, la aristocracia prusiana, los Junkers, no habían permitido el ascenso de la clase media. Además, la incipiente clase media, por el miedo que les provocaba el socialismo, en vez de adoptar los ideales y las metas liberales, pugnaron por un Estado autoritario.

Sin embargo, su proceso de industrialización fue similar al de los demás países europeos. Al respecto, Detlev Peukert sostiene que el Tercer Reich no podría explicarse como una desviación de la modernidad, sino como una patología derivada de su propia lógica. A su parecer, el nacionalsocialismo evidenció las tendencias destructivas propias de la sociedad industrial. El régimen nazi no sería resultado de un hecho singular, sino de la crisis que atravesó durante la República de Weimar y de la incapacidad de la democracia burguesa para resolverla. En este sentido, el NSDAP (Nationalsozialistische

4 Claude Lefort hace notar que, en el marco de la Guerra Fría, la noción de totalitarismo, más que tener pretensiones explicativas, era un instrumento de propaganda de los liberales. Así, se buscaba emparentar al comunismo de la URSS con el régimen nazi. Esta concepción acrítica renunció a comprender a los regímenes totalitarios; en cambio, produjo una categoría con la que estigmatizaba cualquier modelo político que difiriera de la democracia liberal (Lefort 2004: 221).

5 "[Auschwitz] fue también una extensión rutinaria del moderno sistema de producción. En lugar de producir mercancías, la materia prima eran seres humanos y el producto final era la muerte: tantas unidades al día consignadas cuidadosamente en las tablas de producción del director. De las chimeneas, símbolo del sistema moderno de fábricas, salía humo acre producido por la cremación de carne humana. La red de ferrocarriles, organizada con acierto, llevaba a las fábricas un nuevo tipo de materia prima. Lo hacía de la misma manera que con cualquier otro cargamento. En las cámaras de gas, las víctimas inhalaban el gas letal de las bolitas de ácido prúsico, producidas por la avanzada industria química alemana. Los ingenieros diseñaron los crematorios y los administradores, el sistema burocrático que funcionaba con tanto entusiasmo y tanta eficiencia que era la envidia de muchas naciones. Incluso el plan general era un reflejo del espíritu científico moderno que se torció. Lo que presenciamos no fue otra cosa que un colosal programa de ingeniería social..." (Bauman 2011: 29). 
Deutsche Arbeiter Partei) ${ }^{6}$ sería un síntoma de las contradicciones de una época.

De acuerdo con Peukert, Alemania cumplía con las características esenciales de la modernidad clásica: las formas de producción y la organización económica propias del capitalismo avanzado, la burocratización del Estado, la racionalización de la sociedad y la cultura, la normalización y el disciplinamiento de la vida cotidiana. En pocas palabras, igual que los demás Estados europeos, el desarrollo alemán se caracterizó por un orden fundado en la hegemonía de la razón y la ciencia (Crew 1992: 319-328).

2

Después del Holocausto, Dwight Macdonald advirtió que se debía temer más a las personas que obedecen la ley que a quien la viola (Bauman 2011: 180). No se debe perder de vista que el genocidio no se había producido únicamente por la locura de un líder carismático, ni por la irrupción de una muchedumbre incontrolable. O que no se trató de el surgimiento de pulsiones pre-sociales que hasta ese momento habían sido contenidas por la razón. Por el contrario, fue posible por un conjunto de funcionarios disciplinados que respetaban con sumo cuidado los marcos jurídicos. ${ }^{7}$

No es un dato menor que la Constitución de Weimar no tuvo que ser derogada durante el Tercer Reich. A pesar de ser considerada una de las más avanzadas por sus rasgos democráticos, fue un instrumento más al servicio del Führer. Mediante el Decreto para la protección del pueblo y el Estado, promulgado el 28 de febrero de 1933, se declaró una "guerra civil legal". Dicho

6 Partido Nacionalsocialista Obrero Alemán.

7 "El Holocausto había empequeñecido todas las imágenes heredadas y recordadas del mal. Así, invirtió todas las explicaciones conocidas del mal en acción. De repente, se supo que el mal más terrible del que tenía noticia la memoria humana no fue la consecuencia de la disipación del orden sino de una imposición de orden impecable, impoluta e incontestada. No fue obra de una muchedumbre incontrolable y desmandada, sino de hombres en uniforme, obedientes y disciplinados, que se ceñían a las normas y respetaban con meticulosidad el fondo y la forma de sus instrucciones. Pronto se supo que esos hombres, en cuanto se quitaban el uniforme, no eran malos en absoluto. Se comportaban como casi todos nosotros. Tenían esposas a las que amaban, niños a los que mimaban y amigos a los que ayudaban y consolaban si estaban afligidos. Parecía increíble que, en cuanto se ponían el uniforme, esas personas fueran capaces de disparar o gasear o presidir una ejecución o la asfixia de miles de personas, muchas de las cuales eran mujeres, que serían las amadas esposas de otros, y bebés, que serían los niños mimados de otros. Esto también era aterrador. ¿Cómo es posible que la gente normal, como tú y yo, haga cosas así?" (Bauman 2011: 180-181). 
decreto se sustentó en el artículo 48, que consideraba la suspensión de las libertades civiles (Mortati 2010: 203). Formalmente, el decreto nunca fue revocado. Por tanto, el estado de excepción que instauró no terminó hasta el fin del régimen nazi. Sin este acto jurídico, no habría sido posible la eliminación física de los "enemigos políticos" (Agamben 2010: 25).

El propio Adolf Eichmann admitía esta relación paradójica que mantenía el nazismo con la ley: si hubiera estado dispuesto a romper la ley, podría haber salvado muchas vidas. Pero, su sentido del deber lo obligaba a respetar las normas y las jerarquías. ${ }^{8}$ Los juristas encargados de la elaboración de las Leyes Raciales de Núremberg — Ley de la Bandera del Reich, la Ley de Derechos Civiles y la Ley para la Protección de la Sangre y el Honor Alemanes- tuvieron un estricto apego a los principios del derecho positivo. Incluso, Carl Schmitt afirmó que se trataba de una forma jurídica que podría ser tildada como medieval, pero correspondía, por primera vez, a la noción de 'libertad' - Freiheit-. Anteriormente, a su juicio, solo se conocían las libertades estamentales - Libertäten-, las cuales elevaron al plano del derecho la dominación de las potencias extranjeras. A su juicio, se trataba de formulaciones extrañas para la tradición alemana. Así, este conjunto de leyes sería, desde su perspectiva, un ejercicio de la libertad que posee todo Estado para definir sus fundamentos jurídicos. Las Leyes de Núremberg pretendían ser una solución legal de la cuestión judía y, al mismo tiempo, erigían al Partido Nazi como defensor de la esencia y los derechos del 'pueblo' —Volk— (Schmitt 2007: 61-64).

8 'El cumplimiento del 'deber' al fin le condujo a una situación claramente conflictiva con las órdenes de sus superiores. Durante el último año de la guerra, más de dos años después de la Conferencia de Wannsee, Eichmann padeció su última crisis de conciencia. A medida que la derrota se aproximaba, Eichmann tuvo que enfrentarse con hombres de su propia organización que pedían insistentemente más y más excepciones, e incluso la interrupción de la Solución final [...]. Desde el punto de vista de Eichmann, los individuos como Becher eran corruptos, pero la corrupción difícilmente pudo ser causa de su crisis de conciencia, por cuanto, si bien Eichmann no era hombre susceptible de padecer tentaciones de este género, también es cierto que en la época a que nos referimos probablemente llevaba ya varios años rodeado por el espectáculo de la corrupción [...]. Sin embargo, tampoco es imposible que Eichmann desconociera este hecho. A pesar de todo, Eichmann en modo alguno podía ignorar que Himmler, en el otoño de 1942, intentó vender permisos de salida a los judíos eslovacos, a cambio de una suma en moneda extranjera, suficiente para reclutar una división de los SS. Pero ahora, en 1944, en Hungría las cosas eran distintas, no debido a que Himmler se dedicara a los 'negocios', sino debido a que los negocios se habían convertido en la política oficialmente seguida por los superiores de Eichmann. Ya no se trataba, pues, de corrupción" (Arendt 2003: 133-134). 
Incluso, en los territorios ocupados se mantuvo este respeto a la ley. Antes de ser enviados al campo de concentración, a los "enemigos del pueblo" se les retiraba la nacionalidad. Este procedimiento era indispensable para no transgredir los fundamentos de la dogmática del derecho internacional. Al ser desnacionalizados, se les despojaba de cualquier condición política y, por ende, eran reducidos íntegramente a "nuda vida" (Agamben 2001: 40). De este modo, ningún Estado tenía la obligación de defender y reclamar sus vidas.

Los Lager, como figura límite de la modernidad, no solo eclipsaron otras representaciones del mal recordadas hasta ese punto de la historia; también transfiguraron la misma noción del mal que prevalecía en Occidente. En el genocidio nazi se evidenció dramáticamente uno de los nudos gordianos de la dogmática jurídica: la indisociable relación entre la violencia y el derecho. La contradicción del poder soberano puede enunciarse de la siguiente manera: el poder soberano, instaurado para salvaguardar la vida, tiene la potestad de sacrificarla. El Estado es el único que puede asesinar sin que sea acusado de algún delito. Esto se debe a que su poder se funda y se conserva mediante una violencia constitutiva. ${ }^{9}$

\section{3}

La idea de "crisis" es una de las más recurridas en la historiografía de Weimar. Al principio, en el imaginario colectivo, la crisis aludía únicamente a la

9 "Y entre ellas, la más criticada desde la entrada en vigor de las interrogantes del derecho positivo, es la pena de muerte. Y los motivos fueron y siguen siendo tan fundamentales como pobres e imperfectos los argumentos esgrimidos en la mayor parte de los casos. Sus críticos sintieron, quizá sin poder fundamentarlo, probablemente sin querer siquiera sentirlo, que la impugnación de la pena de muerte no se reduce a atacar una medida de castigo o alguna ley aislada, sino que alcanza al derecho en su origen mismo. Si la violencia, una violencia coronada por el destino, es su origen, no será del todo desacertada la presunción de que esa violencia cumbre sobre la vida y la muerte, al aparecer en el orden de derecho, puede infiltrarse como elemento representativo de su origen en lo existente y manifestarse de forma terrible. Con ello, también es cierto que la pena de muerte se aplicaba, en condiciones de derecho primitivas, también a delitos de propiedad, cosa que parece desproporcionada a esas 'circunstancias'. Pero su sentido no era de penalizar la infracción a la ley, sino de establecer el nuevo derecho. Y es que la utilización de violencia sobre vida y muerte refuerza más que cualquier otra de sus prácticas, al derecho mismo. A la vez, el sentido más fino deja entrever claramente que ella anuncia algo corrupto en el derecho, por saberse infinitamente distante de las circunstancias en las que el destino se manifestara en su propia majestad. En consecuencia, el entendimiento debe intentar aproximarse a esas circunstancias con la mayor decisión, para consumar la crítica, tanto de la violencia fundadora como de la conservadora" (Benjamin 2001: 31). 
esfera económica, pero, paulatinamente, esta sensación de desolación invadió otros ámbitos como la política, la moral, la cultura e, incluso, la religión (Graf 2010: 592). No es posible comprender el ascenso del nacionalsocialismo sin considerar la derrota alemana en la Primera Guerra Mundial, el Tratado de Versalles y las dos severas crisis económicas que asolaron la República de Weimar durante la década de los años veinte. Por estos referentes, la época de Weimar se asume como el fracaso de la democracia liberal y la antesala del nazismo, pues ni las instituciones ni los partidos fueron capaces de solventar las demandas de la sociedad. El excesivo formalismo impidió anticipar el ascenso de las facciones más radicales.

En este sentido, la crisis por la que atravesó la democracia de Weimar es semejante a la que actualmente atraviesa la democracia representativa. ${ }^{10}$ Las críticas al régimen parlamentario destacaban su inoperancia, su incapacidad de resolver las necesidades mínimas de la población. Su rechazo era tan intenso y profundo que no podía solventarse mediante un ajuste institucional. No se cuestionaba únicamente la legalidad de las instituciones, sino también su legitimidad. Al igual que hoy, se ponían en duda las reglas y las modalidades del ejercicio del poder y los principios en los que se fundaba. Por ello, paradójicamente, la democracia representativa fue depuesta mediante sus propios mecanismos. Los valores democráticos reconocidos formalmente, como la tolerancia, encuentran su límite en esta insatisfacción generalizada, pues esta pareciera incrementar la popularidad de los movimientos xenófobos, racistas y ultranacionalistas.

1o El derrumbe de la República de Weimar está marcado por una condición paradójica: los propios mecanismos dispuestos por la democracia liberal permitieron el ascenso de fuerzas que, abiertamente, se habían posicionado en su contra. Ciertamente, Adolf Hitler no es nombrado canciller mediante una elección popular. Sin embargo, mediante la construcción de alianzas parlamentarias pudo tomar puestos clave que a la postre le permitirían consolidarse. La profunda crisis que atravesó el régimen posibilitó que fuera depuesto. Hasta hace un par de décadas era impensable que se reivindicaran posiciones similares al nazismo. Pero, debido a la insatisfacción generalizada que han producido las democracias han resurgido grupos de ultraderecha que han presentado posiciones semejantes, en particular en lo que respecta a los migrantes. El discurso de miedo y de odio hacia los migrantes se ha insertado en las agendas públicas de países como Italia, Francia, Holanda e, incluso, Alemania. En América Latina también han ganado terreno algunas expresiones cercanas, en especial se han popularizado algunos discursos racistas y xenofóbicos. Más que tratarse de una coincidencia temporal, indicaría una crisis generalizada de los principios y valores que sostenían los regímenes democráticos. 
En pocas palabras, se evidenció la fragilidad del institucionalismo y del normativismo. El vínculo que Max Weber estableció entre la legitimidad y la legalidad, característico de la modernidad, no era tan profundo como él afirmó (Weber 2002: 707). En estas crisis políticas no había forma de que el derecho positivo legitimara el ejercicio del poder político. Por la evidente decadencia de sus instituciones, es posible sostener la tesis de Agamben, según la cual, la democracia ha fracasado, no por una desviación o un desajuste, sino por ser consecuente con sus valores.

Los poderes y las instituciones hoy no se encuentran deslegitimados porque han caído en la ilegalidad; más bien es cierto lo contrario: la ilegalidad está tan difundida y generalizada porque los poderes han perdido toda conciencia de su legitimidad. Por eso es inútil creer que puede afrontarse la crisis de nuestras sociedades a través de la acción — sin duda necesaria—del poder judicial. Una crisis que golpea la legitimidad no puede resolverse exclusivamente en el plano del derecho. La hipertrofia del derecho, que pretende legislar, sobre todo, antes bien conlleva, por medio de un exceso de legitimidad formal, la pérdida de legitimidad sustancial (Agamben 2013: 12-13).

La democracia liberal, sostiene Benjamin, representa la máxima degeneración de la violencia. Esto lo demuestra a través de la institución policial. Comúnmente se piensa que actúa apegada a derecho. Sin embargo, se encuentra en un punto oscuro, en el que resulta complejo establecer cuáles son sus límites. Además, por la ausencia de un referente metafísico, tiende a reducir el orden jurídico a un mero proceso. Su deber, supuestamente, es garantizar la observancia de la ley. Pero, en muchas ocasiones las competencias que le han sido concedidas son insuficientes para cumplir con este propósito, por ello actúa contrariamente a lo dispuesto por el orden jurídico. La violencia policial no solo es conservadora del derecho; también es su fundadora (Benjamin 2001: 31-32).

A través de esta dualidad podría explicarse la contigüidad entre el poder soberano y la policía. En este punto, es conveniente recordar que, a pesar de las metáforas belicistas a las que se recurrió, la Solución final fue ejecutada como una operación policial. ${ }^{11}$ La declaración de un estado de excepción pro-

11 "El ingreso de la soberanía en la figura de la policía no tiene, pues, nada de tranquilizador. Prueba de ello es el hecho, que no ha dejado de sorprender a los historiadores del Tercer Reich, de que el exterminio de los judíos fue concebido de principio a fin exclusivamente como una operación de policía. Es bien sabido que no se ha podido 
dujo un punto de indiferenciación entre la violencia y el derecho. Justamente, en ese punto, es en el que se mueve la policía, en especial cuando apela a razones como el orden público y la seguridad (Agamben 2001: 90). El poder irrestricto que se le concede a los cuerpos de seguridad pretende responder a una situación de grave peligro. Irónicamente, la "protección de la libertad" significa la suspensión de las leyes que garantizan la libertad.

El Lager es el lugar en el que la excepción se convierte en regla. Se trata de un espacio en el que el orden jurídico normal no está vigente. En este sentido, la excepción coincide con su origen etimológico, ex capere — sacado fuera-. Aquello que no ha sido contemplado por el derecho, se le incluye mediante su exclusión.

Solo porque los campos constituyen, en el sentido que hemos visto, un espacio de excepción, en que la ley es suspendida de forma integral, todo es verdaderamente posible en ellos. Si no se comprende esta particular estructura jurídico-política de los campos, cuya vocación es precisamente la de realizar de manera estable la excepción, todo lo que de increíble se produjo en ellos resulta completamente ininteligible (Agamben 2001: 39).

Quien entraba en un Lager, entraba a un lugar en el que no se podía distinguir entre la excepción y la regla, entre lo lícito y lo ilícito, por lo que carecía de cualquier protección jurídica. Con anterioridad había sido privado de sus derechos. En consecuencia, al no haber ninguna mediación, el ser viviente es arrojado a la nuda vida, es decir, a una vida condenada a la mera existencia biológica, sin ninguna otra cualidad digna de valor. Dicho en otras palabras, en este punto de indiferenciación no existe ninguna división de poderes o alguna otra instancia jurídica que proteja al ser viviente. Ya que los derechos dependen de la ciudadanía, cuando esta se le retira, el poder soberano ya no es responsable del ser viviente. Por tanto, es una vida que puede ser sacrificable.

encontrar nunca un solo documento en el que quede constancia del genocidio como decisión de un órgano soberano; el único documento que poseemos a este respecto son las actas de la conferencia que el 2 de enero de 1942 reunió en Grosser Wansee a un grupo de policías de rango medio y bajo, entre los que solo nos es notorio el nombre de Adolf Eichmann, jefe de la división B-4 de la cuarta sección de la Gestapo. Y solo porque se concibió y se llevó a cabo como una operación de policía pudo tener el exterminio de los judíos un carácter metódico y mortífero. Pero, por el contrario, es precisamente su condición de 'operación de policía' lo que hoy le hace aparecer ante la humanidad civilizada como mucho más bárbaro e ignominioso" (Agamben 2001: 91). 
En la noción de razón imperial se manifiesta abiertamente el poder que vincula la soberanía con la vida. Se trata de una operación que, mediante la idea de productividad, la administra y, en caso extremo, la sacrifica. Al convertirse esta noción en un imperativo, se ha reavivado lo que Benjamin denominaba violencia mítica. Se trata de una violencia constitutiva que opera directamente sobre la vida. En esta forma imperial se revela el núcleo onto-antropológico de la soberanía estatal, expresado en el dominio establecido por la ley. De este modo, mediante la coacción, se inscribe la soberanía en el cuerpo social.

La fuerza del Estado, según Schmitt, surge a partir de lo teológico-político. En términos históricos, desde este ámbito, se organizó la distinción entre amigo y enemigo, principio fundacional de la esfera política. La frase cuius regio, eius religio - 'según el rey, será la religión' - es indispensable para pensar la construcción del modelo de relaciones internacionales en el siglo XVII. Desde esta lógica es que se establece un poder soberano, de carácter unitario. En pocas palabras, el territorio constituía una cláusula de exclusividad, es decir, en el espacio en el que el soberano ejercía su poder no podía existir ninguna otra fuente de autoridad que instituyera normas. En este hecho descansa el carácter absoluto del poder soberano.

Los nuevos magni homines están en igualdad de derechos y se reconocen mutuamente como tales, pero su igualdad como personas que son miembros del reducido círculo de soberanos europeos es distinta de la igualdad que resulta del hecho de que cada uno de ellos, aún el más pequeño, representa un peso en el sistema de equilibrio territorial (Schmitt 2002: 131).

La solución del conflicto confesional no lo hace mediante el principio de la convivencia religiosa, sino que opta por la neutralidad, característica de la soberanía estatal. De este modo, le reconoció a cada soberano cierta exclusividad para decidir dentro de su jurisdicción territorial, tanto en el ámbito público como en el privado. Con esta forma de autoridad se pretendía terminar con las guerras religiosas y, simultáneamente, garantizaba que ninguna otra figura pudiera intervenir en los asuntos internos. La neutralidad, que permitiría la superación del conflicto religioso, fundamentaría la soberanía estatal, pero, paradójicamente, restringe la decisión soberana. Esta forma política se concreta como una no intervención, una tolerancia pasiva. Dicho en otras palabras, conlleva el desentendimiento del conflicto para permitir 
la diversidad de los entes políticos. Por tanto, se fragmenta la unidad de la comunidad política.

Los principios fundacionales del Estado moderno están íntimamente vinculados con la administración y la apropiación del territorio. El territorio constituye un espacio en el que se materializa el orden jurídico-político. Según Schmitt, cualquier "ordenamiento" —Ordnung— sería ininteligible si no se parte de un orden concreto, es decir, del "asentamiento" —Ortung-. A su juicio, no solo como metáfora, el principio fundamental del derecho se encuentra en el nomos inscrito en la tierra.

El nomos alude a la ley aceptada y reconocida, pero no a una ley en particular, sino al conjunto que conformaba el orden jurídico y expresaba un modo específico de estar en el espacio. Por ello, la instauración del orden jurídico, político y económico en la polis estaba vinculado íntimamente con la fijación de la propiedad agraria. De acuerdo con el planteamiento de Schmitt, todo nomos parte de una operación tripartita. Inicialmente, surge de un nehmen, es decir, de un acto de tomar o conquistar, es decir, ocupar y apropiarse de la tierra. También requiere de un teilen, repartir lo tomado, para asignar a cada miembro del colectivo lo que, supuestamente, le corresponde. Además, implica un weiden, un pastoreo, para hacer producir el espacio ocupado (Schmitt 2002: XVI).

Bajo la forma del Estado-nación se organizaron tanto el territorio como la población. Esta forma de adscripción se trató de justificar con elementos apriorísticos que tuvieran en común: la lengua, la historia, la cultura y, sobre todo, el territorio. Sin embargo, estas narrativas no resisten un análisis histórico, ya que, en estos criterios, supuestamente objetivos, es factible encontrar múltiples inconsistencias. En ocasiones, algunas comunidades han sido separadas por las fronteras, y en otras, las han agrupado sin importar que lo único que tienen en común es una autoridad burocrática. En otros casos, existen comunidades que no aspiran a constituirse en un Estado-nación (Hobsbawn 1998: 14).

En su sentido original, la idea de 'nación' evocaba un grupo o un gremio, para distinguirlos de otros grupos con los que coexistían. Por tanto, se usaba como sinónimo de extranjero. Pero, con el tiempo, esta acepción cambiaría, recalcando la relación que se tenía con el lugar o territorio de origen. Así, se insistiría en una descendencia común. La noción de natie implicaba una totalidad de personas que se consideraba que pertenecían al mismo clan o tribu (Hobsbawn 1998: 25). 
Sin embargo, la relación con el territorio es más compleja de lo que se enuncia en primera instancia. Al interior de los Estados, incluso en los europeos, existe una pluralidad étnica, que es negada por la pretensión de homogeneidad. La relación entre la población y el espacio territorial, expresada a través del concepto de 'nación', produjo una ambivalencia. Al mismo tiempo, esta noción se empleaba para aludir al Estado, así como a la sociedad. Será hasta el siglo Xx cuando "nación" significará una unidad política de carácter autónomo.

Las implicaciones políticas de este proceso pueden verse claramente en la Declaración de los Derechos del Hombre y el Ciudadano de 1789. Los derechos del hombre corresponden a una serie de valores metajurídicos que inscriben la nuda vida natural en el orden jurídico político del Estado-nación (Agamben 2001: 25). En el antiguo régimen, la vida no le pertenecía a la corona, sino a una entidad divina. Pero, el Estado moderno ignoró la distinción que hacían los antiguos griegos entre la "vida política" — bios - y la nuda vida —zoé-. Así, se hizo del nacimiento dentro de un espacio determinado el fundamento de la soberanía nacional, distinguiéndose del principio divino de la soberanía monárquica (Agamben 2001: 25-26). De este modo, la inscripción de la ley en la tierra fue, al mismo tiempo, su inscripción en el cuerpo.

Las Declaraciones de derechos han de ser, pues, consideradas como el lugar en que se hace realidad el paso de la soberanía regia de origen divino a la soberanía nacional. Aseguran la inserción de la vida en el nuevo orden estatal que habrá de suceder al derrumbe del Ancien Régime. En que por mediación suya el súbdito se transforme en ciudadano, significa que el nacimiento — es decir, la nuda vida natural - se convierte aquí por primera vez (a través de una transformación cuyas consecuencias biopolíticas solo podemos empezar a valorar ahora) en el portador inmediato de la soberanía (Agamben 20o1: 26).

Esta ficción que subsume la vida al espacio territorial impide separar el nacimiento de la ciudadanía. Esto implica que, solo en su carácter de ciudadano, el ser humano puede exigirle al Estado soberano el respeto a sus derechos. En buena medida, la situación precaria de los inmigrantes se deriva de esta condición, pues, para la trinidad Estado-nación-territorio, el único sujeto de derecho válido es el ciudadano.

En el entorno estatal, se desconoce cualquier rasgo político a los inmigrantes. La gran mayoría, a pesar de encontrarse dentro de regímenes demo- 
cráticos, carecen de derechos políticos. En consecuencia, dado su abandono, permanecen bajo un estatus precario; su vulnerabilidad es una condición indisociable de la lógica soberana contemporánea.

\section{5}

De acuerdo con la definición de Schmitt, el Estado es un modo de estar de una comunidad política que se antepone al del individuo. La homogeneidad $y$, en consecuencia, la negación de la alteridad son dos condiciones inherentes de este modo de estar. Aquellos que lo contravienen son declarados "enemigos" - hostis - , pues su mera existencia pone en tela de juicio el orden soberano (Schmitt 2014: 62-63). Esta lógica, y no la irrupción de impulsos irracionales, fue la que motivó la instauración de los campos de exterminio.

En este sentido, sería factible intuir que la única forma de impedir el resurgimiento de estas instituciones totalitarias sería romper la triada Estadonación-territorio que subsume la vida al poder soberano. La cuestión política debe ser pensada como una condición extraterritorial —o no-territorial一. Esto supondría nuevas formas de relación interestatales e intraestatales. Al respecto, Agamben propone que en lugar de conservar un derecho centrado en la figura del ciudadano se reinterprete a través de la figura del refugiado.

En sentido análogo podremos considerar a Europa no como una imposible 'Europa de las naciones', cuya catástrofe a corto plazo ya entrevemos, sino como un espacio aterritorial o extraterritorial en el que los residentes de los Estados europeos (ciudadanos y no ciudadanos) estarían en situación de éxodo o de refugio y en el que el estatuto del europeo significaría estar-en-éxodo (por supuesto también en la inmovilidad del ciudadano). El espacio europeo establecería así una separación irreductible entre el nacimiento y la nación, y el viejo concepto de pueblo (que, como sabemos, es siempre minoría) podría volver a encontrar un sentido político, contraponiéndose decididamente al de nación (por el que hasta ahora ha sido indebidamente usurpado) (Agamben 2001: 29).

Uno de los esfuerzos más claros de disociar la autoridad estatal del territorio fue planteada por Charles M. Tiebout (1956). Con la expresión "votar con los pies" - vote with the feet-, sugería que los individuos podían formar parte de la comunidad que mejor se adecuara a sus expectativas. A su parecer, este cambio estaba determinado por la voluntad individual. En concreto, proponía que los ciudadanos se pudieran mover libremente respetando un único 
criterio, el costo-beneficio, es decir, si a los individuos se les permitía una libre circulación tenderían a buscar los lugares en los que recibieran mayores ventajas por los impuestos que pagaban.

Los presupuestos del planteamiento de Tiebout son simples. Los ciudadanos son entes móviles y, por tanto, pueden desplazarse de una comunidad a otra, de tal modo que sus expectativas sean satisfechas de la forma más eficiente posible. Para ello, se requiere que los ciudadanos sean capaces de comprender las dinámicas al interior de las comunidades y diferenciar de antemano las diversas situaciones a las que se enfrentarían. Según Tiebout, se asume que existe un amplio número de comunidades entre las que se puede elegir y, también, que pueden absorber de manera constante a los recién llegados. Además, que dichas comunidades no son afectadas por su entorno y pueden ser duplicables en caso de rebasar su número ideal. Así, supuestamente, se garantizaría cierta estabilidad y armonía al interior (Tiebout 1956).

Esta perspectiva hedonista equipara al votante con el consumidor y, por tanto, asume que actúan acordes con la misma racionalidad del mercado. En consecuencia, Tiebout sostenía que los bienes y servicios que proporciona el Estado -escuelas, hospitales, transporte público, vías de comunicación- debían adecuarse a las preferencias de los ciudadanos, los cuales se encargarían de evaluar racionalmente las ventajas comparativas que estos representaban. La capacidad de pago del ciudadano, según Tiebout, debía ponderarse sobre cualquier otro criterio. Así, la autoridad estatal sería reducida a un mero administrador de los recursos.

El mérito de esta propuesta es mostrar la fragilidad de la autoridad, que se hace evidente en el momento en el que se cuestiona la fijación del poder soberano sobre el territorio. Pero, a pesar de este duro cuestionamiento, su crítica no la dirige contra el Estado, sino contra las autoridades locales. Por ello, esta propuesta de movilidad fiscal se concentraría en la efectividad para proporcionar servicios públicos y no prestaría atención a los factores que no están vinculados con el sector inmobiliario.

En otras palabras, la propuesta de Tiebout muestra que las decisiones del Estado deben estar supeditadas a los miembros de la comunidad. Sin embargo, al concentrarse únicamente en el beneficio que pudiera obtener el ciudadano de los bienes públicos, le niega de antemano cualquier rasgo político a la comunidad. La concibe como un espacio neutro en el que se cohabita, privada de cualquier otro rasgo. Por ello, la única satisfacción posible es a través de los bienes, descartando cualquier forma de solidaridad. Por tanto, 
la noción de comunidad que plantea esta movilidad fiscal corresponde, únicamente, al mercado inmobiliario, pues su objetivo es satisfacer los deseos de los habitantes.

Además, se debe agregar que los flujos migratorios contemporáneos no responden a este supuesto. La propuesta queda atada al Estado-nación y su movimiento al interior. En particular, pretende describir el proceso que aconteció en los Estados Unidos a mitad del siglo xx, en el que gran cantidad de personas se mudaron de la ciudad a los suburbios. La capacidad de negociación de los migrantes, tal como supone "votar con los pies", se descarta de antemano, por su situación vulnerable. Pero, si se piensa esta exigencia de desvincular la autoridad estatal del territorio desde otros referentes, es factible contravenir la lógica soberana.

Como contrapunto, existen cosmovisiones no eurocéntricas, en las que la tierra no solo es un espacio que se ocupa, sino en el que se habita. Por tanto, conciben la tierra, en un sentido literal, como una parte constitutiva de la comunidad. Esto implica una forma completamente distinta de estar en la tierra y, en consecuencia, de moverse en ella. En este sentido, el nomadismo representa una postura radicalmente opuesta a la del nomos de la tierra del poder soberano, pues se resiste a ser capturada por el poder soberano. Su relación con el territorio es heterónoma, un orden otro, totalmente distinto al del Estado. La determinación de la vida no depende de la fijación en el espacio, sino, por el contrario, de la movilidad.

Gilles Deleuze describe esta contraposición de manera muy clara. El Estado, al apropiarse del territorio, crea espacios estriados, caminos determinados por los que debe moverse el ser viviente, con el fin de capturarlo y controlar sus cuerpos, sus tiempos y sus ritmos. El Estado implica una sobrecodificación. De esta manera, tiende a identificarse, únicamente, con la segmentación territorial que produce. ${ }^{12}$

El nómada mantiene una dinámica distinta; tiende a mantenerse como línea de fuga. Sus movimientos de desterritorialización suponen una ruptura frente a los procesos de reterritorialización del Estado. Por ello, su habitar no territorial representa, en términos de Deleuze, una "máquina abstracta de

12 “... un Estado deviene totalitario cuando, en lugar de efectuar dentro de sus propios límites la máquina mundial de sobrecodificación, se identifica con ella, al crear las condiciones para una 'autarquía', al hacer una reterritorialización por 'aislamiento', en el artificio del vacío (que nunca es una operación ideológica, sino económica y política)" (Deleuze y Guattari 2004: 227). 
mutación" (Deleuze y Guattari 2004: 227). ${ }^{13}$ Su actuar, al ser desterritorialización y descodificación, implica una afrenta permanente al Estado. Se trata de aquello que se resiste a ser determinado y, sobre todo, que es inasible para el poder soberano.

Tanto los judíos como los gitanos fueron dos de los grupos a los que combatió con mayor ferocidad el Tercer Reich. Probablemente se deba a la relación que tienen sus culturas con el nomadismo. Si se cuestiona su lealtad es, en parte, por su reticencia a ser fijados, a ser determinados por la identidad promovida por el Estado-nación. Entre otras acusaciones, se les señalaba como personas poco fiables. No es que se tuviera memoria de una serie de traiciones; la desconfianza se debía a que su concepto de comunidad y, en consecuencia, su identidad, no estaba atado al del territorio soberano. Para el Estado-nación sería incompatible una formulación como la de Franz Rosenzweig: el ser del judío es el exilio (Rosenzweig 1997: 357).

Por ello la saga genealógica del pueblo eterno no comienza, a diferencia de los pueblos del mundo, por la autoctonía. Vástago de la tierra, y aun eso solo según el cuerpo, es únicamente el padre de la humanidad. El padre de Israel, en cambio, fue emigrante. Su historia, tal como cuentan los libros sagrados, empieza con la orden divina de salir del país de su nacimiento y partir hacia otro que Dios le mostrará. Y el pueblo se convierte en pueblo, tanto en la aurora de su tiempo primigenio como, más adelante, en la luz clara de la historia, en un exilio: primero, en el desierto de Egipto; luego, en el de Babilonia. Y la patria que cultiva y en la que hace su morada la vida de un pueblo del mundo, hasta casi olvidar que ser un pueblo quiere decir algo más que posar en el país, tal patria nunca llegó a ser propia en ese sentido para el pueblo eterno. No se le ha concedido el albergue excesivo de un hogar. Conserva siempre la falta de atadura de uno que va de viaje, y es más fiel paladín de su tierra cuando está fuera de ella de correría y aventuras y cobra nostalgia de la patria que dejó, que en los tiempos que se queda en casa (Rosenzweig 1997: 357).

Mientras el Estado no deja de producir segmentos duros para capturar las líneas de fuga, los nómadas no dejan de crear líneas de fuga. Los nómadas se

13 "la máquina abstracta atravesaba todas las estratificaciones, se desarrollaba única y por sí misma en el plan de consistencia constituyendo su diagrama, la misma máquina actuaba tanto sobre la astrofísica como sobre la microfísica, lo natural como lo artificial, y dirigía flujos de desterritorialización absoluta (evidentemente, la materia no formada no era en modo alguno un caos cualquiera)" (Deleuze y Guattari 2004: 227). 
conducen, en un sentido etimológico, de forma excéntrica, es decir, fuera del centro. Por tanto, se separan y se reagrupan constantemente. En este sentido, por su desarraigo al territorio —o, mejor dicho, por su relación distinta con la tierra-, siempre se teme que en algún momento voten con los pies, es decir, que decidan abandonar el territorio que habitan. De este modo, no existiría algún lazo que los atara al poder soberano. Sería un error pensar que la ruptura que representan se debe a su incapacidad y su desinterés por ajustarse al control del poder soberano. Más bien, se debe a que encarnan una comunidad política que responde a una lógica distinta.

El nomadismo, más que ser una clasificación étnica, implica un modo de vida distinto al sedentarismo. Por ejemplo, el aprecio que tiene el beduino por el secreto se asemeja a la estima que el ciudadano occidental tiene por el carácter público del Estado. Sin duda, su sola existencia pone en evidencia el carácter ficticio de la triada "Estado-territorio-vida" en el que se funda la soberanía moderna y, en consecuencia, la noción de 'ciudadanía'. Su resistencia a cualquier determinación revela que la 'ciudadanía' representa una estratagema de las relaciones de poder, es decir, para ser sujeto de derechos se debe estar sujeto al derecho.

Pierre Clastres, con gran lucidez, dio cuenta de la profunda ruptura que implican las comunidades sin Estado. Las comunidades que Clastres estudia, al igual que los nómadas, no están fijados al espacio, tal como impone el nomos de Occidente. Por su concepción evolucionista de la historia, para la tradición europea, el Estado correspondía a la materialización de la civilidad y del progreso. Por ello, asumían que todas las sociedades debían transitar hacia un modelo estatal jerarquizado. Sin embargo, las estructuras políticas de las sociedades primitivas eran ininteligibles si se partía de las categorías occidentales. Esa era la razón fundamental por la que se asumía que la ausencia de Estado significaba una incompletitud, característica de sociedades no civilizadas. Como si se tratase de un axioma, no solo implicaba una forma en la que se organizaba una sociedad, sino la forma a la que toda sociedad debía aspirar. $^{14}$

14 "Lo que de hecho se enuncia es que las sociedades primitivas carecen de algo —el Estado - que, sin embargo, les es necesario, como a cualquier otra sociedad — por ejemplo, la nuestra-. Por lo tanto, estas sociedades están -incompletas-. No son, en absoluto auténticas sociedades - no están civilizadas-, subsisten en la experiencia quizá dolorosa de una carencia — carencia de Estado- que intentarán colmar, pero siempre en vano" (Clastres 2011: 183). 
En el caso de estas comunidades, la ley no es una condición a priori de la adscripción política. Por el contrario, en estas comunidades, mediante un rito de iniciación, se debe consentir ser miembros con plenos derechos. Según Kafka, tal como lo muestra en la parábola Ante la ley, el derecho es un secreto que se resiste a ser develado; por tanto, es inaccesible para los miembros de la comunidad (Kafka 2008). En cambio, en estas comunidades, el secreto se revela a los jóvenes en la superficie de sus cuerpos, porque a partir de él se funda la vida común. ${ }^{15}$ En consecuencia, nadie está autorizado a olvidarlo.

Vosotros sois de los nuestros. Cada uno de vosotros es igual a nosotros, cada uno de vosotros es igual a los demás. Lleváis el mismo nombre y no lo cambiaréis. Cada uno de vosotros ocupa entre nosotros el mismo espacio y el mismo lugar: lo conservaréis. Ninguno de vosotros es menos que nosotros, ninguno de vosotros es más que nosotros. Y no podréis olvidarlo. Incesantemente, las mismas marcas que hemos dejado en vuestros cuerpos os lo recordarán (Clastres 2011: 180).

Los primeros cronistas de la Conquista insistían en que eran comunidades sin ley. Ciertamente, ignoraban la ley del rey, la del Estado. Su carácter asimétrico contravenía la ley inscrita en sus cuerpos, que pretendía que el poder no se escindiera de la comunidad. La lección más importante de esta ley primitiva es la prohibición de la desigualdad. Y era imperativo que se tuviera memoria de ello.

En este sentido, el rasgo más importante de la jefatura en estas comunidades es la ausencia de autoridad. La jefatura es un poder impotente, que tiene la responsabilidad de hacer la paz y conservar la armonía, de ser generoso y de ser buen orador. El poder coercitivo es aceptado únicamente en situaciones particulares, como la guerra. Las decisiones están supeditadas al consensus ómnium y no a la coerción. La potencia de esta jefatura radica en su capacidad de convencimiento y no en la fuerza. De ese recurso depende la subsistencia de la comunidad. Esta jefatura sin autoridad revela la interdependencia entre el grupo, pues, más que un privilegio, representa una responsabilidad.

La potencia de esta forma impotente de jefatura se revela a través de la figura del chamán y portavoz Davi Kopenawa, quien a partir de las tradicio-

15 "Numerosas sociedades primitivas señalan la importancia que otorgan a la entrada de los jóvenes en la edad adulta por la institución de ritos llamados de pasaje. Estos rituales de iniciación constituyen a menudo un eje esencial con relación al cual se ordena en su totalidad la vida social y religiosa de la comunidad. Ahora bien, casi siempre el rito de iniciación pasa por tomar en consideración el cuerpo de los iniciados. 
nes del pueblo yanomami ha articulado una dura crítica a la política estatal y a la economía de mercado. Su capacidad de comunicarse con la mayoría lusófona, le ha permitido mostrar una forma distinta de ejercer el liderazgo de la comunidad, más parecida al profeta que al rey. En vez de reproducir la lógica soberana al interior de la comunidad, la interpela. Este particular punto desde el que enuncia, le permite comprender, por ejemplo, que la política proteccionista del Estado brasileño, en vez de favorecer a los indígenas, al fragmentarlos, ha profundizado las relaciones asimétricas.

A la violencia física que han sufrido estas comunidades se suma una violencia simbólica, que niega la validez de su forma de vida. En este sentido, los reclamos de Kopenawa difieren de otras formas de resistencia. En Europa, en la primera mitad del siglo xx, las minorías étnicas aspiraban a ser asimiladas dentro del marco estatal. La exigencia yanomami es distinta; se trata de una integración en la esfera política, sin que esto implique una renuncia a su forma de vida. En este sentido, se plantea un diálogo necesario entre los derechos civiles y los derechos de la naturaleza. Estas singularidades son las que le permiten hablar no solo en nombre de su comunidad, sino también encarna el reclamo de otras víctimas de los conflictos inherentes al Estado y al mercado.

El rasgo fundamental del nomadismo no es la posibilidad de abandonar un territorio, sino la capacidad de moverse en él como si se tratase de un espacio liso, la variación constante. Por el contrario, la razón de ser del Estado es detener dichas variaciones, capturar los flujos, sin importar que se trate de poblaciones o mercancías. La vocación del Estado por contener todo lo que lo desborda representa el mayor obstáculo para el nómada, pues se trata de un movimiento turbulento. Incluso es capaz de modular estas líneas de fuga, controlando los flujos, las trayectorias y los movimientos. Pero, así como el

Es el cuerpo que la sociedad designa inmediatamente como único espacio propio para llevar el signo del tiempo, la huella de un pasaje, la asignación de un destino. ¿A qué secreto inicia el rito que, por un momento, toma posesión del cuerpo del iniciado? Proximidad, complicidad del cuerpo y del secreto, del cuerpo y de la verdad que revela la iniciación: reconocer eso conduce a precisar el interrogante. ¿Por qué es necesario que sea el cuerpo individual el punto de unión del ethos tribal?, ¿por qué el secreto solo puede ser comunicado mediante la operación social del rito sobre el cuerpo de los jóvenes? El cuerpo mediatiza la adquisición de un saber, ese saber se inscribe sobre el cuerpo. Naturaleza de ese saber transmitido por el rito, función del cuerpo en el desarrollo del rito: cuestión en la que se resuelve la del sentido de iniciación" (Clastres 2011: 175-176). 
sedentarismo constituye un freno para el nomadismo, la vida nómada no deja de afectar la vida sedentaria.

Y siempre que se produce una acción contra el Estado, indisciplina, sublevación, guerrilla o revolución como acto, diríase que una máquina de guerra resucita, que un nuevo potencial nomádico surge, con reconstitución de un espacio liso o de una manera de estar en el espacio como si fuera liso (Deleuze y Guattari 2004: 390).

En este sentido, el modo nómada, que escapa a la triada Estado-territorio-vida, revela al mismo tiempo los elementos constitutivos del poder soberano y la posibilidad de establecer un punto de partida para afrontar la crisis de la democracia de manera completamente distinta. Ya que el pensamiento reaccionario insiste en negar la crisis por la que atraviesa la democracia representativa, se vuelve urgente plantear la comunidad política bajo nuevos parámetros. La exaltación de la legalidad como un principio sustancial superior, asegurando que la legitimidad es un epifenómeno o un efecto, ha provocado que el Estado-nación sea incapaz de comprender el sentido de la crisis por la que atraviesa. No reconocen que la legalidad y la legitimidad son parte de la misma maquinaria política. No se puede sobreponer una sobre la otra; de algún modo, ambas siempre se mantienen operando. En este sentido, ya no es posible sostener la idolatría de la ley fijada en la tierra e inscrita en el cuerpo. El reclamo por derechos ha rebasado las capacidades del nomos soberano.

En la democracia, la "voluntad popular" es el principal elemento legitimador del ejercicio del poder. De acuerdo con Agamben, la crisis por la que atraviesa la democracia contemporánea se debe a la fractura de este concepto. Por una parte, está el 'Pueblo' que corresponde a esa unidad originaria que ha constituido el Estado. Por otra, está el 'pueblo', el sector desposeído. Ambas nociones son mutuamente excluyentes. Y no será posible que coincidan si no se cuestiona de antemano la asimetría que supone el poder soberano y, consecuentemente "Estado-territorio-vida".

La propuesta de Tiebout: "votar con los pies", inicialmente, implicaba el cálculo racional para establecer un lugar en el que se puedan tener los mayores beneficios al menor costo posible. Sin buscarlo, ha dejado entrever que la autoridad estatal se funda en la apropiación del territorio. En la desterritorialización es posible encontrar la principal apuesta para desarticular el poder soberano. Si se traduce el planteamiento de Tiebout a la experiencia nómada, 
sería posible pensar la comunidad sin estar sujeto a las contradicciones de la democracia representativa.

\section{Bibliografía}

Agamben, Giorgio (200o). Lo que queda de Auschwitz el archivo y el testigo. Valencia, Pre-Textos.

Agamben, Giorgio (2001). Medios sin fin. Notas sobre la política. Valencia, Pre-Textos.

Agamben, Giorgio (2010). Homo Sacer. El poder soberano y la nuda vida. Valencia, Pre-Textos.

Agamben, Giorgio (2013). El misterio del mal. Benedicto XVI y el fin de los tiempos. Buenos Aires, Adriana Hidalgo.

ARENDT, Hannah (2003). Eichmann en Jerusalén. Un estudio acerca de la banalidad del mal. Barcelona, Lumen.

Bauman, Zygmunt (2011). Modernidad y Holocausto. Madrid, Sequitur.

Benjamin, Walter (2001). "Para una crítica de la violencia", Iluminaciones IV. Para una crítica de la violencia y otros ensayos. Madrid, Taurus: 21-45.

Clastres, Pierre (2011). La sociedad contra el Estado. Córdoba, Tierra del Sur.

CREW, David F. (1992). "The Pathologies of Modernity: Detlev Peukert on Germany's Twentieth Century", Social History, vol. 17, núm. 2: 319-328.

Deleuze, Gilles, y Félix GuatTari (2004). Mil mesetas. Capitalismo o esquizofrenia. Valencia, Pre-Textos.

GrAF, Rüdiger (2010). "Either-Or: The Narrative of 'Crisis' in Weimar Germany and in Historiography”, Central European History, vol. 43, núm. 4: 592-615.

Hobsbawn, Eric (1998). Naciones y nacionalismos desde 1780. Barcelona, Crítica.

KAFKA, Franz (2008). El proceso. Madrid, Alianza Editorial.

LEFORT, Claude (2004). La incertidumbre democrática: ensayos sobre lo político. Barcelona, Anthropos.

Mortati, Costantino (2010). La Constitución de Weimar. La constitución alemana de 11 de agosto de 1919. Madrid, Tecnos.

RosenzWeig, Franz (1997). La estrella de la redención. Salamanca, Ediciones Sígueme.

Sснмітт, Carl (2002). El nomos de la tierra en el derecho de gentes del "Ius publicum europeaum". Granada, COMARES.

Schмiтt, Carl (2007). "La Constitución de la libertad", en Yves Charles Zarka, Un detalle nazi en el pensamiento de Carl Schmitt. Barcelona, Anthropos Editorial: 61-64.

Schмiтt, Carl (2014). El concepto de lo político. Madrid, Alianza Editorial.

Tiebout, Charles Mills (1956). "A Pure Theory of Local Expenditures", Journal of Political Economy, vol. 64, núm. 5: 416-424.

WEBER, Max (2002). Economía y sociedad. Esbozo de sociología comprensiva. Madrid, Fondo de Cultura Económica. 


\section{Jorge A. Rodríguez Martínez}

Doctor en Ciencias Políticas y Sociales, con orientación en Ciencia Política, por la Facultad de Ciencias Políticas y Sociales de la UNAM. Investigación en desarrollo: "La soberanía y el monopolio de la violencia legítima en el Estado moderno. Un estudio del debate Benjamin-Schmitt en torno a la teología política y el estado de excepción". Participante en el proyecto PAPIIT "Heteronomías de la justicia: territorialidades nómadas" del Instituto de Investigaciones Filológicas de la Universidad Nacional Autónoma de México. 